\title{
End-of-pipe or cleaner production? How to go green in presence of income inequality and pro-environmental behavior ${ }^{\text {th }}$
}

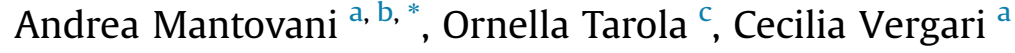 \\ a Department of Economics, University of Bologna, Strada Maggiore 45, 40125 Bologna, Italy \\ ${ }^{\mathrm{b}}$ Barcelona Institute of Economics (IEB), C/ J. M. Keynes 1-11, 08034 Barcelona, Spain

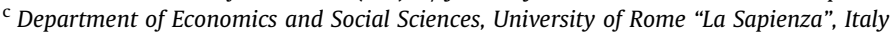

\section{A R T I C L E I N F O}

\section{Article history:}

Received 29 March 2016

Received in revised form 24 November 2016

Accepted 20 January 2017

Available online $\mathrm{xxx}$

\section{JEL classification:}

d62

L13

H13

Keywords:

Relative preferences

Hedonic quality

Environmental quality

End-of-pipe technology

Cleaner technology

\begin{abstract}
A B S T R A C T
In this paper we consider a vertically differentiated duopoly model in which a green producer competes with a brown rival in a market in which consumers are environmentally concerned. In particular, consumers are assumed to value not only the intrinsic quality of a certain product, but also its environmental impact. This environmental valuation has a positional content: consumers attach a positive attribute to the green product, while penalizing the brown one. In this context, we consider the choice of the green firm between cleaner and end-of-pipe abatement efforts. We find that the interplay between the intensity of market competition, consumers' income disparity and environmental concern can play a crucial role in directing the green producer towards one or the other technological choice. More precisely, the adoption of cleaner production technologies can be discouraged by low average income and by tough competition, while it can be spurred by the moral/social incentive towards pro-environmental behavior.
\end{abstract}

(ㄷ) 2017 Elsevier Ltd. All rights reserved.

\section{Introduction}

Recent years have shown a growing interest for environmental issues all over the planet. Due to mass-media and informative campaigns by local governments, people have become increasingly concerned with the impact of their consumption choices on the ecosystem in which they live. This may be driven by personal motivations, as people realize that looking after the environment affects their standard of living (Heffner et al., 2007; Carlsson et al.,

\footnotetext{
\# We are grateful to the Editor Rodrigo Lozano, to the Guest Editor Silvester Ivanaj, and to four anonymous referees for very detailed comments that have led to substantial imrpovements of the paper. We are also thankful to Anna Montini, Francesco Silvestri, and the audience at UECE Lisbon Meetings in Game Theory and Applications 2016, 4th IAERE (Italian Association of Environmental and Resource Economists) Annual Conference, and University of Bologna for precious comments and discussion. We thank Lucy Scioscia for editorial assistance. The usual disclaimer applies.

* Corresponding author. Department of Economics, University of Bologna, Strada Maggiore 45, 40125 Bologna, Italy.

E-mail addresses: a.mantovani@unibo.it (A. Mantovani), ornella.tarola@ uniroma1.it (O. Tarola), cecilia.vergari@unibo.it (C. Vergari).
}

2010; Deltas et al., 2013). Yet, another strand of the literature points out that social and moral motivations represent the main drivers to green consumption (Brekke et al., 2003; Nyborg et al., 2006; Manner and Gowdy, 2010). In this view, people feel that they comply with a social norm when they buy green products. Green consumers receive therefore some degree of social approval, and this may increase their level of integration in a society (Ostrom, 2000). Conversely, consumers may incur a sort of social stigma when they buy brown products.

The green content of social norms usually differs according to a country's cultural orientation as well as the intergenerational transmission from parents to children (Litina et al., 2016). For this reason, a consumer's environmental concern is often countryspecific. Producers may then decide to adjust their environmental technological efforts to the socio-economic conditions of the market that they confront. Toyota, for example, offers a wide range of vehicles, and some of them are characterized by a prominent effort in reducing polluting emissions. Apart from the popular Prius hybrid and plug-in hybrid models, Toyota is also making significant investments in small electric vehicles as well as larger hydrogen fuel cell commercial vehicles. Toyota's segmentation strategy is 
driven by its philosophy of marketing the "right car in the right place". Toyota's Corolla sedan car is designed for drivers who are looking for a prestigious car, whereas the aforementioned Toyota Prius targets more environmentally concerned drivers. Case in point, Corolla is more popular in Thailand than in Japan and in the U.S., as in the latter countries environmental sensitivity is growing and hybrid vehicles are receiving increasing attention. However, also in those markets where consumers have not yet developed an environmental conscience, Toyota has to cope with new challenges coming from environmental regulations, which often require to sustain some costs in order to reduce the pollution emissions level of its vehicles.

It follows that green technological efforts usually differ, depending on whether the producer aims at capturing consumers' environmental concern, or if it simply must satisfy a tighter environmental regulation. We want to investigate whether a firm that wants to "go green" is more willing to invest in cleaner production rather than in end-of-pipe technologies in the presence of social incentives to pro-environmental behavior. Many authors have pointed out that, although both abatement efforts enable a firm to comply with a given environmental regulation, cleaner or "beginning-of-the-pipe" technologies are usually preferable to "end-ofpipe" or "end-of-the-pipe" technologies for both environmental and economic reasons (Frondel et al., 2007; Requate, 2005). Indeed, while the former technologies reduce pollution emissions at the source since they entail a change in the production process, the latter ones are simply add-on measures that curb emissions at the end of the production process. ${ }^{1}$ This explains why the cost related to cleaner production is usually assumed to be variable in the quantity produced, whereas with an end-of-the-pipe investment technologies, the cost is assumed to be fixed (Clemenz, 2010; Nicolaï and Meunier, 2014). More precisely, the cleaner the technology is, the lower the per-unit of output emissions but the higher the marginal production costs are. On the contrary, in the case of end-of-pipe technologies, some fraction of the pollutant is reduced without changing the production process. For this reason, although both technologies require (at least in the short run) an increase of the production costs, cleaner technologies could potentially improve the production process in the long run. ${ }^{2}$

Understanding the driving factors that affect firms' propensity to implement one technology instead of the other one represents therefore a relevant research question. While most of the literature focuses on the impact of different forms of environmental regulation, we depart from this approach and focus on the interplay between the respective costs of the two different green technologies, the intensity of market competition and the degree of consumers' environmental concern.

\subsection{Our modeling framework}

In order to formally address our research issue, we consider a duopoly market with two firms each providing a vertically differentiated good to a population of consumers. The intrinsic functionality of a product determines its hedonic quality so that the high quality variant is characterized by a better performance.

\footnotetext{
${ }^{1}$ A similar distinction is often labeled as abatement versus replacement technologies. Abatement technology refers to the reduction of polluting emissions for a given production technology, while replacement technology implies a substitution of the brown technology with the green technology.

2 Typical examples of end-of-pipe technologies are catalytic convertors on automobile tailpipes that reduce pollutant emissions after they have formed, whereas examples of cleaner production technologies are the use of environmentally friendly materials (e.g. replacing organic solvents by water) and modification of the combustion chamber design (process-integrated systems).
}

Nonetheless, the high quality variant has very high emissions. Accordingly, it is more polluting than the low quality alternative. The green (but low hedonic quality) variant can be produced by using either a cleaner technology (i.e. incurring a variable cost) or end-of-pipe measures (i.e. incurring a fixed cost).

It follows that, building on Mantovani et al. (2016), we restrict our attention to the case in which consumers face a trade-off between the intrinsic performance of a product and its environmental impact. Most electric or hybrid vehicles, although characterized by a lower environmental impact, are still less performant than conventional internal combustion engine vehicles in terms of speed and overall driving experience. However, consumers may receive some additional benefit from the less polluting vehicle if there exists a sufficiently strong pro-environmental social norm ingrained in the society. On this point, we are very close to the literature on impure altruism as a source of pro-social behavior (Andreoni, 1988, 1990). Indeed, we argue that consumers experience positive feelings from green behavior as they believe they "are doing the right thing".

Furthermore, since the contribution to the environment is socially more valuable in a highly polluted community, we assume that the social benefit deriving from green consumption depends on the comparison between the emissions released by the green product and those released by the brown alternative. Symmetrically, the more polluting the product chosen by an individual is in comparison with the green alternative, the stronger the social condemn. ${ }^{3}$ Hence, in our model, the relative position of a product on the environmental quality ladder defines the relative position of a consumer on the social ladder. We capture the social dimension of consumption in the form of relative preferences in which the satisfaction of a consumer is also determined by the difference between the personal status and the status of the others (Akerlof, 1997; Alexopoulos and Sapp, 2006; Reichmann, 2006). ${ }^{4}$ In this setting, we investigate how the choice between cleaner and end-of-pipe technologies is solved by the green (but low hedonic-quality) firm, given the relative cost entailed by each type of abatement effort.

It is worth remarking that we disregard the uncertainty that often affects R\&D activity, in this case related to the green technology. We acknowledge that this is a relevant issue, which has attracted a limited but significant number of contributions, such as Denicolò (1999), Montero (2011) and Scotchmer (2011). These authors consider stochastic models with replacement technologies that are affected by different environmental policies, and are characterized by an explicit trade-off between static and dynamic efficiency. However, this would go beyond the scope of our analysis, as it would imply introducing a time dimension. Furthermore, it would depart from the main idea motivating our paper, namely the effects of pro-environmental behavior and income inequality on how to go green.

\subsection{Our main results}

We find that in extreme cases, i.e. when the cost difference unambiguously favors one technology versus the other, then the firm opts for the cheaper solution. For example, if the marginal cost required by cleaner technology is comparatively much higher than

\footnotetext{
3 Since the conspicuous consumption theory developed by Veblen (1899), consumers are willing to pay a higher price for a functionally equivalent good in order to reveal their wealth, their social status or other specific characteristics.

${ }^{4}$ In his pioneering paper, Akerlof (1997) stated that the satisfaction of a consumer increases with the difference between the personal status and the status of the others. Alexopoulos and Sapp (2006) and Reichmann (2006) analyze relative preferences from the point of view of firms. These preferences are also known as "other-regarding preferences".
} 
the fixed cost required by end-of-pipe technology, then the latter always prevails. This is rather obvious given the assumptions of the model.

Instead, our analysis provides interesting results when the cost difference is intermediate. In this case, the solution to the conflict between green technologies is related to the willingness to pay (WTP henceforth) for quality, which depends on both the consumer's degree of green awareness and her average income. ${ }^{5}$ In particular, we find that for high (resp. low) level of income, the investment in cleaner technologies (resp. end-of-pipe) is unambiguously preferred over end-of-pipe (resp. cleaner technologies). For intermediate values of income, whenever the emissions gap between the variants is low (resp. high), then investing in cleaner can be observed only in the uncovered (resp. covered) market.

The rationale underlying this result is as follows. When facing the choice between investing in cleaner $v s$. end-of-pipe technologies, the green firm takes into account two drivers: a price competition driver and a social driver. These two drivers have to be examined by considering the basic difference between these two abatement efforts. In particular, while investing in cleaner technologies implies a variable cost disadvantage which in turn increases the price charged at equilibrium, end-of-pipe measures do not directly affect the equilibrium price since the fixed cost does not enter into the firm's maximization process. Accordingly, cleaner technology can be preferred over end-of-pipe as long as the firm can benefit from a high WTP, that can be considered increasing with income (see Tirole, 1988; page 96). On the one hand, the price competition driver discourages the investment in cleaner technology given that equilibrium prices decrease with the intensity of market competition. On the other hand, the social driver acts in an opposite sense as it increases the WTP for the green good.

We find that the price competition driver dominates for high values of WTP for intrinsic hedonic quality, regardless of the market coverage, thus explaining why end-of-pipe technology prevails for low values of income, whereas cleaner production prevails for high values of income. This is consistent with recent findings. Frondel et al. (2007), for example, find a clear dominance of cleaner production in seven OECD developed countries (Canada, France, Germany, Hungary, Japan, Norway, and the U.S.).

For intermediate values of income, the balance of these contrasting drivers is ambiguous. The social driver is stronger the larger the social component of consumption is, namely the higher is the intensity of the relative preferences and/or the higher is the emissions gap. The competition driver is more significant in a covered market where the equilibrium market shares react more strongly to a price change than in the uncovered market. Since full market coverage is reached thanks to high enough values of the intensity of social preferences, it follows that, on one hand competition is tougher, but on the other hand, the social component of consumption is more important in the covered than in the uncovered market. Thus, the choice between cleaner and end-ofpipe technologies depends on whether the competition driver inducing the green firm to invest in cleaner technologies in the uncovered market - dominates (or is dominated by) the social driver, leading the green firm to undertake this investment in the covered market. Whenever the emissions gap is not very relevant, the competition driver prevails so that the green firm undertakes an investment in cleaner technologies in the uncovered market, while it opts for end-of-pipe technologies under market coverage. On the contrary, when the emissions gap is relevant, the social

\footnotetext{
${ }^{5}$ On the relationship between inequality and green consumerism, see the seminal paper by Boyce (1994), along with following contributions by Magnani (2000), Vona and Patriarca (2010), and Pfaff et al. (2004), inter alia.
}

driver prevails so the investment in cleaner technologies takes place only in the covered market where the increase in price due to the variable cost does not penalize significantly the green firm in terms of market share.

It is worth remarking that a low emissions gap can be considered as a small environmental innovation, that is, the environmentally friendly firm is unable to substantially differentiate its variant with respect to the brown good. In this case, it is therefore preferable to invest in cleaner production only in an uncovered market where competition is milder than in a covered one.

The structure of the paper is as follows. In Section 2 we provide the literature review. In Section 3 we outline the formal model and derive demand functions. In Section 4 we develop the equilibrium analysis for both cleaner and end-of-pipe technologies. In Section 5 we compare these two green technologies and provide economic and managerial intuition to explain the firm's decision. Section 6 concludes the paper.

\section{Related literature}

Our paper mainly contributes to two different strands of literature: consumers' environmental awareness and end-of-pipe versus cleaner technology. To the best of our knowledge, we are the first to analyze in a unified setting the relationship between green consumerism and the dilemma of end-of-pipe versus cleaner technologies when consumers face a trade-off between the intrinsic performance of a product and its environmental impact.

On the one hand, increasing attention has been paid to the impact of green consumerism on market equilibrium. Most of this literature has focused on green high quality goods competing with brown low quality goods (Eriksson, 2004; Moraga-Gonzalez and Padron-Fumero, 2002; García-Gallego and Georgantzís, 2009; Ben Elhadj and Tarola, 2015; inter alia). Considering again the automotive sector, Tesla or Lexus produce vehicles that combine remarkable performance and environmental sustainability. Other examples can be found in sectors such as organic food (Whitewave Foods), fair trade certified clothing (Patagonia), and energy-saving devices (energy-efficient light bulbs), where high hedonic quality standards are achieved in combination with environmental quality. ${ }^{6}$ Nonetheless, the case of a conflict between performance and environmental attribute has recently received increasing attention (Conrad, 2005; Mantovani et al., 2016; inter alia). ${ }^{7}$ We are in line with these last works, which cover situations such as recycled paper $v$. paper produced from trees (that is often preferred because it is softer to the touch), recycled $v s$. virgin plastic (that is more pliable to process), new generation washing machines' energy saving cycles labeled "green" or "eco" vs. ordinary cycles (that are less time consuming).

On the other hand, a large debate has focused on which type of green R\&D activity should be carried out by producers, and which policies should be adopted to incentivize the adoption of green technologies (Montero, 2002; Requate and Unold, 2003; Requate, 2005; inter alia). Once again, mainstream contributions assume that the high quality good is also green, and this is the result of different forms of R\&D activities. In Arora and Gangopadhyay (1995), Moraga-Gonzalez and Padron-Fumero (2002) and Bansal and Gangopadhyay (2003) firms invest to increase the environmental quality of a product. Quality improvements require fixed

\footnotetext{
${ }^{6}$ In general, B-corps aim to achieve a high performance while still maintaining a commitment to environmental sustainability and protection. Visit: https://www. bcorporation.net/.

7 Deltas et al. (2013) consider different attributes of a good in a duopoly where products differ both vertically (in terms of their "greenness") and horizontally (e.g., design, style, brand, and convenience).
} 
setup costs. Differently from our model, however, consumers do not incorporate in their utility function the impact of pollution emissions. In Amacher et al. (2004) and Lombardini-Riipinen (2005), environmental quality refers to the cleanness of production, and abatement efforts affect the variable costs. A common objective of these papers is to study different forms of policy interventions in support of green production. We abstract from policy instruments as we focus on the incentive on how to "go green" in presence of a social component of consumption which contrasts the vertical attribute of a product. ${ }^{8}$ To a certain degree, our paper can be related to endogenous mechanisms that drive firms to adopt green technologies. André et al. (2009) and Lambertini and Tampieri (2012) use a vertical differentiation model with environmental qualities to support the Porter hypothesis, showing that firms may adopt green technologies even in absence of regulation. ${ }^{9}$

By explicitly considering how green consumerism affects the choice between end-of-pipe and cleaner technologies, we relate our analysis to the branch of behavioral economics that extends standard economic models based on the homo economicus in order to incorporate the formation of pro-environmental behaviors coming from moral/social motivations (Brekke et al., 2003; Nyborg et al., 2006; Manner and Gowdy, 2010; Owen and Videral, 2006; Turaga et al., 2010; inter alia) or from "warm-glow" considerations (Andreoni, 1988, 1990; Bergstrom, 1995; inter alia). ${ }^{10}$ We share with this literature the argument that a pro-social behavior may be determined by the desire to obtain a laudable social image, and that the effects of social image concerns increase with the visibility of the activity (Béenabou and Tirole, 2006; Andreoni and Bernheim, 2009). Indeed, in our approach, the pro-environmental behavior is a conspicuous practice and as such it is mainly driven by a social component. In particular, we consider that the source of this component is a social norm stating that protecting the environment is a byword for good citizenship. Following this view, we assume that: $(i)$ the social reward/punishment increases with the emissions differential between the green and the brown variant, thus capturing the relative contribution of a consumer to the environment; (ii) an exogenous parameter measures the strength of the social norm. Notice that, when removing these social and/or "warm-glow" aspects of environmental concern, buying a green good per se does not increase the utility of an environmentally concerned consumer. Typically, it is the total demand of the green good that affects consumers' utility by determining the amount of total emissions. However, this would require a different framework entailing a network effect whereby the utility from buying either good would depend on the number of consumers purchasing that good. In so doing, the relative pull of dirty consumers would affect the social reward/punishment. ${ }^{11}$

We nest in our setting the choice between end-of-pipe and cleaner technologies, as we want to investigate whether these relative preferences affect the profitability of one technology versus the other. Contributions on this choice are mainly devoted to analyzing the impact of environmental regulation on the decision of the producer regarding which green technology to adopt (Calel,

\footnotetext{
8 Mantovani and Vergari (2017) consider the role of environmental campaign vs. taxation under relative preferences.

${ }^{9}$ According to the Porter hypothesis (Porter, 1990; Porter and van der Linde, 1995), environmental regulation, instead of reducing profit opportunities, may induce firms to carry out new forms of innovative activities, ultimately resulting in higher profits.

10 The warm glow theory argues that people may help others in order to feel good about their contributions. Donors, for example, may receive utility from the mere act of giving.

11 For theoretical contributions on product differentiation and network effects, see Grilo et al. (2001) and Garcia and Vergari (2016), among others.
}

2011; Christin et al., 2013; Frondel et al., 2007; Johnstone et al., 2010; Nicolaï and Meunier, 2014). ${ }^{12}$ There is common agreement on two main findings. First of all, while regulation (such as pollution taxes) has a positive and significant impact on investment in end-ofpipe measures, this does not hold in the case of cleaner technologies (Frondel et al., 2007). The reason is that end-of-pipe measures are easier to carry out in order to lower the burden of pollution taxes, given that they are not integrated within the production process. Secondly, there is an increasing trend of investment in cleaner technologies, and this is mainly observed in developed countries, as we stressed above (see again Frondel et al., 2007). Since they change the whole production process, cleaner technologies are somehow intended as a second step toward abatement effort, the first step being rather represented by end-of-pipe measures.

Our results are in line with this evidence. We find that the adoption of cleaner technologies is widespread in high-income countries, where the willingness to pay for quality is sufficiently high. Also, we describe how a social driver contributes to solve the dilemma between end-of-pipe and cleaner technology, thereby highlighting the role that can be played by consumers' environmental awareness rather than different forms of government intervention (such as taxes and pollution permits). Incidentally, our position can be somehow reconciled with the idea that the choice of end-of-pipe versus cleaner technologies can be explained by a mix of market-pull (i.e. a tendency to prefer environmentally friendly products) and technology-push (i.e. subsidies) factors, with market-pull factors being expected to be more important for investment in cleaner technologies than for end-of-pipe measures (see Hemmelskamp, 1997).

Furthermore, by combining income levels and environmental awareness in order to describe the incentive for producers to adopt green technologies, our paper relates to several studies that attempted to evaluate the impact of economic growth on environmental commitment. In particular, several studies have found an inverted-U relationship between economic growth and environmental degradation. This relationship has been defined as the Environmental Kuznets Curve, and suggests environmental degradation increases in the early stages of growth, and then decreases when income reaches a certain point over the course of development (see, inter alia, Borghesi, 2001; Dinda, 2004, 2005). One of the factors highlighted by this view is that a higher level of income enables consumers to develop a certain degree of environmental awareness, thus contributing to shifting production toward more environmentally friendly activities. More recently, Schumacher (2015) explained how environmental culture can induce this relationship in an overlapping generation model. Namely, only "once society has reached a certain level of economic development, then it may optimally invest a part of its wealth in developing an environmental culture", that in turn induces society to improve environmental quality, "which again drives increases in environmental culture" (p. 201). Somewhat in line with these studies, our results suggest that for high level of income and/or high social awareness the more environmentally friendly technology choice prevails.

Finally, our analysis contributes to a large strand of the literature investigating the interplay between environmental regulation and firms' location. Even before the formulation of the pollution haven hypothesis (Copeland and Taylor, 2004), this literature received ample attention from scholars (see, among others, Markusen et al.

\footnotetext{
12 A remarkable exception is Clemenz (2010), who analyzes the effect of eco-labels on polluting emissions in a model with horizontal differentiation. He finds that the impact of eco-labels depends on the abatement effort undertaken by firms: an efficient abatement level is more likely to be achieved with clean production than with end-of-pipe technology.
} 
1993, 1995; Motta and Thisse, 1994; Greaker, 2003). Some of them focused on the optimal environmental policy within a given market structure (Bayindir-Upmann, 2003; Kayalica and Lahiri, 2005; Cole et al., 2009), while others endogenized both location and policy decisions under market symmetry (e.g. Petrakis and Xepapadeas, 2003; Ulph and Valentini, 2001; Abe and Zhao, 2005; Ikefuji et al., 2016). Finally, a part of them developed the analysis under the assumption of country asymmetry (Zeng and Zhao, 2009; Sanna-Randaccio and Sestini, 2012), or both country and firm heterogeneity (Sanna-Randaccio et al., 2016) with exogenous unilateral climate policies. In our case, we do not focus on the effects of unilateral policies on firms' location. However, we still analyze how the dilemma between end-of-pipe and cleaner technologies is solved in the light of market features, such as income and environmental awareness. Thus, we implicitly advance the hypothesis that country heterogeneity plays a role in the choice of abatement effort and therefore, depending on the area where a firm decides to install its plant, the choice of abatement changes. For example, we find that for a high level of income, or when the social component is extremely significant, the investment in cleaner technologies is preferred over end-of-pipe. In this view, our results thus contribute to highlight that market-pull factors can induce firms to prefer cleaner technologies, in spite of their possibly high costs.

\section{The model}

We consider two firms producing two vertically differentiated goods. Similarly to the models of vertical differentiation (Mussa and Rosen, 1978), the performance of good $i$, with $i=L, H$, determines its intrinsic or hedonic quality $q_{i}$ with $q_{H}>q_{L}$. Nevertheless, good $q_{i}$ generates polluting emissions per unit of production at some level $e_{i}=\phi q_{i}$. As a result, given that $e_{L}=\phi q_{L}<e_{H}$, good $H$ represents the brown good, whereas good $L$ represents the green good. Still, variant $L$ is less polluting than variant $H$. We consider two possibilities for the green firm $L$ to produce the environmentally friendly good: either invest in cleaner or invest in end-of-pipe technologies (Frondel et al., 2007). ${ }^{13}$ In line with the literature, we model cleaner technologies with variable costs and end-of-pipe technologies with fixed costs (see, among others, Clemenz, 2010).

As far as the demand side is concerned, we consider a continuum of consumers indexed by $\theta$ and uniformly distributed in the interval $[0, b]$ with density $1 / b$. The parameter $\theta$ is proportional to the WTP for intrinsic quality, so that $b$ denotes the highest WTP for the performance of a product. Typically, parameter $b$ represents the highest level of income among consumers: the higher the income, the higher the corresponding willingness to pay of consumers. ${ }^{14}$ The indirect utility of consumer type $\theta$ writes as:

$U(\theta)=\left\{\begin{array}{c}\theta q_{H}-p_{H}-\gamma\left(e_{H}-e_{L}\right), \text { if she buys the high quality good, } \\ \theta q_{L}-p_{L}+\gamma\left(e_{H}-e_{L}\right), \text { if she buys the low quality good, } \\ 0, \text { if she refrains from buying. }\end{array}\right.$

The utility from consumption depends on both the variant's hedonic quality $q_{i}$ and the emissions gap between variants. This latter component, i.e. $\gamma\left(e_{H}-e_{L}\right)$, captures the idea that the variants are perceived as positional goods. Therefore, they are considered by consumers in terms of relative instead of absolute emissions. For the sake of simplicity and without any loss of generality, we can

\footnotetext{
${ }^{13}$ We assume without loss of generality that it is firm $L$ to undertake abatement effort. We shall discuss briefly later how our main findings would change under the alternative assumption that it is firm $H$ to carry out abatement efforts.

14 See for example Gabszewicz and Thisse (1979) and Shaked and Sutton (1982).
}

assume that $\phi=1$, so that $\left(e_{H}-e_{L}\right)=\left(q_{H}-q_{L}\right){ }^{15}$ So, these emissions fix the relative position of a variant along an environmental quality ladder and thus determine the corresponding social position of consumers along the social ladder. ${ }^{16}$

Accordingly, although the quality is unidimensional and hedonic, each consumer incorporates the emission differential in its surplus function due to the social component of consumption. Parameter $\gamma \geq 0$ measures the intensity of this relative dimension of consumption, namely the strength of the social norm inducing a pro-social (and green) behavior. ${ }^{17}$ Following Litina et al. (2016), we assume that social norms are uniformly interiorized by the citizens living in the same country. The rationale supporting this view is that a community shares the same set of cultural values and beliefs (Dietz et al., 2005; Steg and de Groot, 2012) and thus expresses the same willingness to comply with a social norm. This assumption implies that, for each given level of $\gamma$, someone with high income appreciates relatively less a good with high environmental concern. Indeed, we advance the idea that whenever people attribute a very high value to the hedonic component, they are less prompt to sacrifice the consumption of a product with a very high performance because it is polluting. They do not accept the environmentally friendly nature of a good as a compensation for a poor performance. $^{18}$

From the above formulation of the utility function, the consumer indifferent between buying the low quality good and not buying at all, and the one indifferent between buying the low quality good and the high quality good, are respectively given by:

$\theta_{L}=\frac{p_{L}-\gamma\left(q_{H}-q_{L}\right)}{q_{L}}$,

$\theta_{H}=\frac{2 \gamma\left(q_{H}-q_{L}\right)+p_{H}-p_{L}}{q_{H}-q_{L}}$.

The demand functions faced by firms $L$ and $H$ are easily derived:

$$
\begin{aligned}
x_{L}= & \frac{1}{b}\left(\theta_{H}-\max \left\{\theta_{L}, 0\right\}\right) \\
& =\left\{\begin{array}{c}
\frac{1}{b}\left[\frac{p_{H} q_{L}-q_{H} p_{L}+\gamma\left(q_{H}+q_{L}\right)\left(q_{H}-q_{L}\right)}{q_{L}\left(q_{H}-q_{L}\right)}\right] \text { if } \gamma<\frac{p_{L}}{q_{H}-q_{L}}, \\
\frac{1}{b}\left(2 \gamma+\frac{p_{H}-p_{L}}{q_{H}-q_{L}}\right) \text { if } \gamma \geq \frac{p_{L}}{q_{H}-q_{L}} .
\end{array}\right.
\end{aligned}
$$

$x_{H}=\frac{1}{b}\left(b-\theta_{H}\right)=\frac{1}{b}\left[b-\left(2 \gamma+\frac{p_{H}-p_{L}}{q_{H}-q_{L}}\right)\right]$,

\footnotetext{
15 We could consider a generic $\phi>0$ without normalizing $\phi$ to 1 . However, this would not bring any further insight to the model while making the analysis extremely cumbersome.

16 See Ben Elhadj et al. (2015) for an in-depth discussion of this formalization. An alternative way to model the utility function would be relating the satisfaction of an individual when consuming a hedonic quality variant with its absolute environmental quality. In this latter formulation however, the status or positional content of green consumption would not be captured.

17 The higher the value of $\gamma$, the stronger the relative (or social) preferences with respect to the hedonic ones. The extreme case $\gamma=0$ reduces the model to the traditional vertical differentiation framework with hedonic preferences as unique driver for consumption.

18 Of course, this trade-off does not arise when a good is simultaneously of high hedonic quality and green. In this case, consumers can satisfy their desire to comply with a social norm while consuming a high hedonic quality product. Notice that a good satisfying simultaneously both the hedonic and the social requirements provide consumers with a higher surplus than the alternative one, even if people
} are not interested in one of the two requirements. 
As for the supply side, we assume that either firm can produce only one type of product, intended as a combination of the two attributes (hedonic quality and emissions): this captures the idea that it is costly and time-consuming for a firm to go green. ${ }^{19}$ For example, the switch to solar power requires the installation of solar panels on business facilities. Moreover, the cost reductions in energy savings are not always enough to counterbalance the conversion costs, at least in the short run. Therefore, it is reasonable to assume that the production choice is irreversible: each firm $i$ produces the variant $q_{i}$, corresponding to a given hedonic and environmental attributes. Further, we assume that production costs are positive only for the green good, whereas the brown quality is produced at zero cost. Formally, profit functions of firms $H$ and $L$ respectively write as:

$\pi_{H}=x_{H} \cdot p_{H}$,

$\pi_{L}=\left\{\begin{array}{c}\left(p_{L}-c\right) x_{L} \text { under cleaner production } \\ x_{L} \cdot p_{L}-F \text { under end }- \text { of }- \text { pipe production }\end{array}\right.$

where $c>0$ is the per-unit cost in case of cleaner technology, whereas $F$ is the fixed cost in case of end-of-the-pipe technology. This cost specification, despite its simplicity, enables us to address the question of whether a green firm is more willing to invest in cleaner production rather than in end-of-pipe technologies in the presence of moral/social incentive to pro-environmental behavior.

\section{The equilibrium analysis}

Typically, in a traditional vertically differentiated duopoly market in which the lowest WTP for quality is zero, firms never end up covering the market at equilibrium. However, in this framework, characterized by relative preferences, we can identify the conditions for which the market is covered at the limit. In particular, this happens when the intensity of relative preferences is sufficiently strong. In Mantovani et al. (2016) we characterize the parametric region where this happens for the case of cleaner technology; in the following analysis we add those for the end-of-pipe technology.

It is also possible to show that the green (resp., brown) firm can monopolize the market when the intensity of relative preferences is extremely high (resp., low). However, for the purpose of the present paper, we limit our analysis to the case in which both producers are active in the market. ${ }^{20}$ In particular, we consider two market configurations: duopoly with uncovered market and duopoly with covered market. This enables us to analyze the key role of competition on the green firm's decision between cleaner and end-of-pipe technology. Without loss of generality, we limit the analysis to the case where the quality ratio is such that $q_{H} / q_{L} \in(1,2)$, but the results can be easily generalized to account for each quality specification $q_{H}>q_{L}{ }^{21}$ In the following analysis we distinguish our equilibrium results according to the type of green technology adopted by the firm.

\footnotetext{
${ }^{19}$ We also focus on the case in which firms produce different qualities so as to exclude that price competition leads to a Bertrand paradox.

20 Additional calculations and formal demonstrations are available upon request. In Mantovani et al. (2016) we characterize such conditions for the case of cleaner technology, identifying the parametric regions where a monopoly (either green or brown) may occur at equilibrium.

${ }^{21}$ In the next subsections we will characterize the parametric regions in which a duopoly scenario holds, both for the case of cleaner and for the case of end-of-thepine technology. Assuming $q_{H} / q_{L} \geq 2$ would imply considering other relevant threshold values for $\gamma$ and $b$, given that some of our conditions require different threshold values precisely when $q_{H} / q_{L}>2$. However, given that the qualitative results of our paper are unaffected by the quality ratio that we adopt, we decided to focus on the case $q_{H} / q_{L} \in(1,2)$. Additional calculations are available upon request.
}

\subsection{Cleaner technology}

In case of cleaner technology, the environmentally friendly firm incurs in a per-unit cost disadvantage equal to $c$, given that the production cost for the brown producer is assumed to be zero. Sufficient but not necessary conditions for the duopoly equilibria (both uncovered and covered) to hold are summarized in Lemma 1. Necessary conditions are specified in Appendix A but they are not used throughout the paper in order to simplify the exposition of our results. This is without loss of generality, as one can easily prove. Let us define:

$$
\begin{aligned}
\widehat{b} & \equiv \frac{c q_{H}}{\left(q_{H}-q_{L}\right)^{2}}, \\
\underline{\gamma} & \equiv \frac{c\left(2 q_{H}-q_{L}\right)-b q_{L}\left(q_{H}-q_{L}\right)}{2 q_{H}\left(q_{H}-q_{L}\right)}, \\
\widehat{\gamma} & \equiv \frac{2 c q_{H}+b\left(q_{H}-q_{L}\right) q_{L}}{\left(2 q_{H}-q_{L}\right)\left(q_{H}-q_{L}\right)} .
\end{aligned}
$$

Lemma 1. Provided $b>\widehat{b}, \theta_{L}<\theta_{H}<b$ so that both firms are active in the market when $\gamma \in[\max \{0, \gamma\}, b)$. The duopoly is sustained by an interior equilibrium for $\gamma \in[\max \{0, \gamma\}, \widehat{\gamma})$, while it is sustained by a corner equilibrium with market coverage for $\gamma \in[\widehat{\gamma}, b)$.

\section{Proof. See Appendix A.}

Under cleaner production, price competition leads to the following equilibrium profits in the uncovered market equilibrium (superscript $C$ stands for Cleaner):

$$
\begin{gathered}
\pi_{L}^{C}=\frac{q_{H}\left[\left(q_{H}-q_{L}\right)\left(2 \gamma q_{H}+b q_{L}\right)-c\left(2 q_{H}-q_{L}\right)\right]^{2}}{b q_{L}\left(q_{H}-q_{L}\right)\left(4 q_{H}-q_{L}\right)^{2}}, \\
\pi_{H}^{C}=\frac{\left\{c q_{H}+\left(q_{H}-q_{L}\right)\left[2 b q_{H}-\gamma\left(3 q_{H}-q_{L}\right)\right]\right\}^{2}}{b\left(q_{H}-q_{L}\right)\left(4 q_{H}-q_{L}\right)^{2}} .
\end{gathered}
$$

As for the covered market equilibrium (additional superscript cov indicates a covered market):

$\pi_{L}^{C_{c o v}}=\frac{(b+\gamma)\left[\gamma\left(q_{H}-q_{L}\right)-c\right]}{2 b}$

$\pi_{H}^{C_{\text {cov }}}=\frac{(b-\gamma)^{2}\left(q_{H}-q_{L}\right)}{4 b}$

Equilibrium profits in both cases are obviously positive under Lemma 1. Equilibrium prices and demands for both cases are reported in Appendix A and indicated with $p_{i}^{C}$ and $x_{i}^{C}$ for the uncovered case and with $p_{i}^{C_{\text {cov }}}$ and $x_{i}^{C_{\text {cov }}}$ for the covered case, respectively, with $i=L, H$. Although important for the following analysis, we decided not to report their precise expressions in the main text in order to focus only on the most important calculations, which will focus on profits' comparisons.

\subsection{End-of-pipe technology}

In case of end-of-the-pipe technologies, there is a fixed cost disadvantage for the green firm as variable costs are assumed to be zero for both firms. We focus again on sufficient but not necessary conditions for both the uncovered and the covered duopoly to be sustained at equilibrium. Necessary conditions are reported in Appendix B but they are again neglected in the formal analysis for expository purposes. Let us define: 
$\widehat{b}^{\prime} \equiv \frac{F\left(2 q_{H}-q_{L}\right)^{2}}{q_{H} q_{L}\left(q_{H}-q_{L}\right)}$,

$\underline{\gamma^{\prime}} \equiv \frac{\left(4 q_{H}-q_{L}\right) \sqrt{F b q_{H} q_{L}\left(q_{H}-q_{L}\right)}-b q_{H} q_{L}\left(q_{H}-q_{L}\right)}{2 q_{H}^{2}\left(q_{H}-q_{L}\right)}$,

$\widehat{\gamma}^{\prime} \equiv \frac{b q_{L}}{2 q_{H}-q_{L}}$.

Lemma 2. Provided $b>\widehat{b}^{\prime}, \theta_{L}<\theta_{H}<b$ andboth firms are active in the market when $\gamma \in\left[\max \left\{0, \gamma^{\prime}\right\}, b\right)$. The duopoly is sustained by an interior equilibrium for $\left.\gamma \in\left[\max \left\{0, \underline{\gamma}^{\prime}\right\}, \widehat{\gamma}^{\prime}\right\}\right)$, while it is sustained by a corner equilibrium with market coverage for $\gamma \in\left[\widehat{\gamma}^{\prime}, b\right)$.

\section{Proof. See Appendix B.}

Under end-of-pipe production technologies, equilibrium profits in the uncovered market equilibrium are (superscript $E$ stands for end-of-pipe):

$\pi_{L}^{E}=\frac{q_{H}\left(q_{H}-q_{L}\right)\left(b q_{L}+2 \gamma q_{H}\right)^{2}}{b q_{L}\left(4 q_{H}-q_{L}\right)^{2}}-F$,

$\pi_{H}^{E}=\frac{\left(q_{H}-q_{L}\right)\left(2 b q_{H}-3 \gamma q_{H}+\gamma q_{L}\right)^{2}}{b\left(4 q_{H}-q_{L}\right)^{2}}$.

They are obviously positive under the conditions specified in Lemma 2. Equilibrium prices and demands for the uncovered case are indicated with $p_{i}^{E}$ and $x_{i}^{E}, i=L, H$. Their precise expressions are reported in Appendix B.

As for the covered market equilibrium, prices and demands are the same as under cleaner production: $p_{i}^{E_{c o v}}=p_{i}^{C_{c o v}}$ and $x_{i}^{E_{c o v}}=x_{i}^{C_{c o v}}$, $i=L, H$. Equilibrium profit for the brown producer do not change $\left(\pi_{H}^{E_{c o v}}=\pi_{H}^{C_{c o v}}\right)$ while that of the green firm is given by:

$\pi_{L}^{E_{\text {cov }}}=\frac{\gamma(b+\gamma)\left(q_{H}-q_{L}\right)}{2 b}-F$,

and it is positive under Lemma 2 .

Before proceeding to the formal comparison between the two technologies, notice that in both scenarios the market is covered for sufficiently high values of $\gamma$. In other words, when the social component of consumption is perceived as extremely relevant, the green firm gains consumers both at the expense of the brown rival $\left(\theta_{H}\right.$ shifts to the right) and among those who previously decided not to buy the product ( $\theta_{L}$ shifts to the left). Our conditions for a covered duopoly market guarantee that $\theta_{L}=0$ but at the same time $\theta_{H}<b$, otherwise the brown producer would be induced to exit from the market.

\section{Cleaner versus end-of-pipe technology}

Imagine a preliminary stage of the price game in which the firm that goes green can choose between cleaner and end-of-thepipe technology. Which one is it going to adopt? And what is the potential role of social preferences and income in affecting such a decision? We are aware that the relative cost of the two technologies plays an important role, but we want to study what happens when such cost difference is not the primary driver of the decision.

Let us now proceed by assessing whether the green firm is more willing to invest in cleaner rather than in end-of-pipe technologies in the two market configurations. First of all, we need to find the

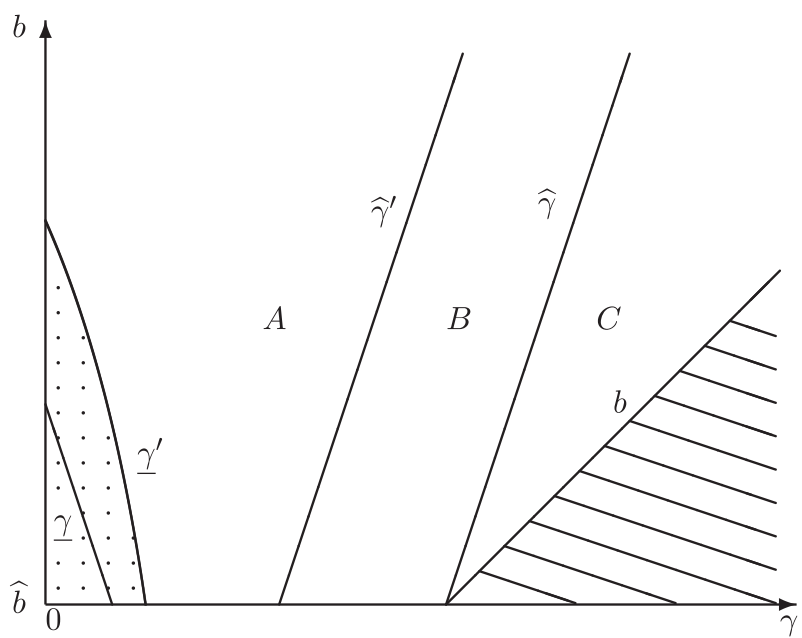

Fig. 1. Parametric regions sustaining duopoly at equilibrium.

precise parametric regions in which both firms are active at equilibrium under both green efforts. Considering the conditions appearing in Lemmas 1 and 2, it follows that:

Lemma 3. Provided $b>\max \left\{\widehat{b}, \widehat{b}^{\prime}\right\}$, an uncovered duopoly can be sustained at equilibrium under both technologies when $\gamma \in\left[\max \left\{0, \underline{\gamma}, \underline{\gamma}^{\prime}\right\}, \widehat{\gamma}^{\prime}\right)$, while a covered duopoly can be sustained at equilibrium under both technologies when $\gamma \in[\widehat{\gamma}, b)$. For $\gamma \in\left[\widehat{\gamma}^{\prime}, \widehat{\gamma}\right)$, the equilibrium would result in an uncovered duopoly under cleaner technology and in a covered duopoly under end-of-pipe technology.

Proof. See Appendix C.

Fig. 1 reproduces the parametric regions described in Lemma 3, under the assumptions that $q_{H}=1.5, q_{L}=1$, and that $F$ is sufficiently high with respect to $c$ so that $\gamma^{\prime}>\gamma$ and $\widehat{b}>\widehat{b}^{\prime} .{ }^{22}$ The shaded area in the south-east portion of the figure represents the region where $\gamma \geq b$, while the dotted area in the south-west portion illustrates the case in which $\gamma<\max \left\{0, \underline{\gamma}, \underline{\gamma}^{\prime}\right\}$. The former area is characterized by an equilibrium in which only the green firm is active in the market, given the strong intensity of relative preferences. On the contrary, in the latter area the green firm cannot survive at equilibrium, because the cost that it has to pay to become green is too high in comparison with the (very) weak combination between the WTP for quality and the degree of the moral/social motivation for consumption. ${ }^{23}$

Consider first the (sub)set of relevant parameters where an uncovered duopoly arises at equilibrium with both end-of-pipe and cleaner technology. This corresponds to area $A$ in Fig. 1, which is characterized by the condition $\gamma \in\left[\max \left\{0, \underline{\gamma}, \underline{\gamma}^{\prime}\right\}, \widehat{\gamma}^{\prime}\right)$. Comparing equilibrium profits we find:

\footnotetext{
$\overline{22}$ Following the calculations reported in Appendix $C$, this holds when $F>F_{0}$. This is without loss of generality, as a similar representation would have resulted for lower values of $F$. The only relevant change in the graphic would have been the fact that $\gamma^{\prime}<\gamma\left(F \leq F_{0}\right)$ and that eventually also $\widehat{b}<\widehat{b}^{\prime}$ for very low values of $F$ $\left(F<\overline{F_{1}}<\overline{F_{0}}\right)$.

${ }^{23}$ In Mantovani et al. (2016) the interested reader can find detailed information on the characterization of the all the possible equilibria appearing for the case of cleaner production. Additional information can be provided for the case of end-ofpipe investment effort.
} 


$$
\begin{aligned}
\pi_{L}^{C}-\pi_{L}^{E}= & F-c q_{H}\left(2 q_{H}-q_{L}\right) \\
& \times \frac{4 q_{H}\left(q_{H}-q_{L}\right) \gamma-c\left(2 q_{H}-q_{L}\right)+2 b q_{L}\left(q_{H}-q_{L}\right)}{b q_{L}\left(q_{H}-q_{L}\right)\left(4 q_{H}-q_{L}\right)^{2}} .
\end{aligned}
$$

It is immediate to prove that for very low values of $F$ with respect to $c$ (think of $F \rightarrow 0$, for example), then end-of-pipe would be always preferred by the green producer. The opposite would result, mutatis mutandis, for a very high value of $F$ relatively to the value of $c$. The most interesting situations occur therefore for intermediate values of $F$ with respect to $c$. In particular,

$$
\pi_{L}^{C}-\pi_{L}^{E} \gtreqless 0 \Leftrightarrow b \gtreqless \frac{c q_{H}\left(2 q_{H}-q_{L}\right)\left[4 q_{H}\left(q_{H}-q_{L}\right) \gamma-c\left(2 q_{H}-q_{L}\right)\right]}{q_{L}\left(q_{H}-q_{L}\right)\left[F\left(4 q_{H}-q_{L}\right)^{2}-2 c q_{H}\left(2 q_{H}-q_{L}\right)\right]} \equiv b^{F} .
$$

However, $b^{F}$ is compatible with $\gamma \in\left[\max \left\{0, \gamma, \gamma^{\prime}\right\}, \widehat{\gamma}^{\prime}\right)$ when $F \in\left[F_{1}, F_{2}\right)$, where the precise value of $F_{1}$ is reported in Appendix $C$, and

$$
F_{2}=\frac{2 b q_{L}\left(4 q_{H}^{2}-5 q_{H} q_{L}+q_{L}^{2}\right)-c\left(2 q_{H}-q_{L}\right)^{2}}{b q_{L}\left(q_{H}-q_{L}\right)\left(4 q_{H}-q_{L}\right)^{2}} .
$$

We can therefore state the following:

Proposition 1. In an uncovered duopoly, when $F \in\left[F_{1}, F_{2}\right)$, the green firm prefers to invest in cleaner (resp. end-of-pipe) technology when $b>b^{F}$ (resp. $\left.b \leq b^{F}\right)$.

Proof. Directly follows from previous discussion. In particular, it is relatively easy to demonstrate that $F_{2}>F_{1}$ when $b>\max \left\{\widehat{b}, \widehat{b}^{\prime}\right\}$.

Consider next the (sub)set of relevant parameters where a covered duopoly arises at equilibrium with both end-of-pipe technologies and cleaner production. This corresponds to area $C$ in Fig. 1, where $\gamma \in[\widehat{\gamma}, b)$. Comparing relevant equilibrium profits, we obtain:

$\pi_{L}^{C_{c o v}}-\pi_{L}^{E_{c o v}}=F-\frac{c(b+\gamma)}{2 b}$

Obviously, given $b$ and $\gamma$, if $F$ is sufficiently high with respect to $c$, then cleaner technology always prevails, and the opposite when $F$ is low enough. For intermediate values of $F$, we find that:

$\pi_{L}^{C_{\text {cov }}}-\pi_{L}^{E_{c o v}} \gtreqless 0 \Leftrightarrow b \gtreqless \frac{c \gamma}{(2 F-c)} \equiv b^{c o v}$.

The threshold value $b^{\text {cov }}$ is compatible with $\gamma \in[\widehat{\gamma}, b)$ when $F \in\left[F_{3}, c\right)$, where,

$F_{3}=\frac{c q_{H}\left[c+b\left(q_{H}-q_{L}\right)\right]}{b\left(q_{H}-q_{L}\right)\left(2 q_{H}-q_{L}\right)}$.

To sum up, we can state that:

Proposition 2. In a covered duopoly, when $F \in\left[F_{3}, c\right)$, the green firm prefers to invest in cleaner (resp. end-of-pipe) technology when $b>b^{\text {cov }}$ (resp. $\left.b \leq b^{\text {cov }}\right)$.

Proof. Directly follows from previous discussion. In particular, it is immediate to demonstrate that $F_{3}<c$ when $b>\max \left\{\widehat{b}, \widehat{b}^{\prime}\right\}$.

Propositions 1 and 2 reveal that a firm that decides to adopt a green technology prefers to (unilaterally) invest in cleaner rather than in end-of-pipe solutions when the average WTP for quality in the market is sufficiently high. The intuition is as follows: the adoption of cleaner technology, that entails a variable cost disadvantage and in turn it raises the equilibrium prices, is discouraged by tough competition - that is for low values of parameter $b$. In other words, the incentive for the green firm to invest in cleaner technologies increases with the average income, which softens competitive pressure. Thus, in high-income countries (regions), the incentive to invest in the production process dominates the incentive to undertake add-on-measures.

Even though we restricted our analysis to the range of $\gamma$ and $b$ parameters where either an uncovered or a covered market arises at equilibrium with both technology choices (respectively Areas $A$ and $C$ in Fig. 1), our results also hold in Area B. In other words, when $\gamma \in\left[\widehat{\gamma}^{\prime}, \widehat{\gamma}\right.$ ), we obtain a $b$-threshold value such that cleaner (resp. end-of-pipe) dominates end-of-pipe (resp. cleaner) technologies when $b$ is above (resp. below) this threshold. ${ }^{24}$

Let us now consider how the incentive to invest in cleaner versus end-of-pipe technology changes with the market coverage. We find that:

Proposition 3. For high (resp. low) values of $b$, the investment in cleaner technologies (resp. end-of-pipe) is unambiguously preferred over end-of-pipe (resp. cleaner) technologies. For intermediate values of $b$, whenever the quality gap is low (resp. high), then investing in cleaner technologies can be observed only in the uncovered (resp. covered) market.

Proof. see Appendix D.

The rationale underlying the above Proposition can be explained as follows. When facing the dilemma between investing in cleaner or end-of pipe technologies, the green firm takes into account two drivers: a price competition driver and a social driver. These two drivers have to be read by considering the basic difference between these two abatement efforts: while investing in cleaner technologies entails a variable cost disadvantage thereby raising the equilibrium price, end-of-pipe measures do not affect directly the equilibrium price since they entail a fixed cost. Accordingly, the former investment can be preferred over the latter as long as the firm can benefit from a high WTP for quality. An investment in cleaner technologies is indeed stifled by the price competition driver given that competitive pressure reduces equilibrium prices, while it is spurred by the social driver as this increases the WTP for the green good. The price competition driver prevails for extreme values of $b$, regardless of the market coverage (this is the same intuition behind Proposition 1 and 2). This explains why end-ofpipe technologies are adopted for low values of $b$, whereas cleaner production is preferred when $b$ is high enough. For intermediate values of $b$, the balance of these contrasting drivers is ambiguous. The social driver is stronger the larger is the social component of consumption $\left(\gamma\left(q_{H}-q_{L}\right)\right)$, that is the higher is the intensity of the relative preferences $(\gamma)$ and/or the higher is the quality gap $\left(q_{H}-q_{L}\right)$. The competition driver is more significant, in a covered market, where the equilibrium market shares react more strongly to a price change than in the uncovered market. Since the covered market is characterized by values of $\gamma$ which are higher than in the uncovered market, on one hand competition is tougher, but on the other hand the intensity of social preferences becomes more relevant in the covered than in the uncovered market. Thus, the choice between cleaner versus end-of pipe technologies depends on whether the competition driver - inducing the green firm to invest in cleaner technologies in the uncovered market - dominates (or is dominated by) the social driver - leading the green firm to undertake this investment in the covered market.

\footnotetext{
$\overline{24}$ Additional calculations are available upon request.
} 
Whenever the quality gap is not very relevant, the competition driver prevails so the green firm undertakes an investment in cleaner technologies in the uncovered market, while preferring to invest in end-of-pipe under market coverage. On the contrary, when the quality gap is relevant, the social driver prevails so the investment in cleaner technologies takes place only in the covered market where the increase in price due to the variable cost does not penalize significantly the green firm in terms of market share. ${ }^{25}$

Finally, let us briefly consider how these findings are related to the assumption that it is firm $L$ to undertake the abatement effort. To this aim, let us focus on the alternative assumption that it is firm $H$ to invest in abatement. Then, firm $H$ would produce a variant that is of higher quality along both hedonic and environmental dimensions. In this case, the conflict between the price competition and the social drivers would not arise since both of them would lead to the same type of investment. Indeed, the willingness to pay for hedonic quality would be magnified by the existence of social preferences, so that a high value of $b$ and/or $\gamma$ would induce firm $H$ to prefer cleaner technologies over end-of-pipe measures. Then, as an immediate consequence, firm $H$ would favor cleaner production for high values of $b$, while it would prefer to invest in end-of-pipe technologies in the opposite case. The range of $b$ - parameters for which cleaner technologies are preferred becomes larger (resp. smaller), the higher (resp. lower) the value of $\gamma$.

\section{Conclusions}

We have analyzed the role of price competition in the technological choice between cleaner and end-of-pipe abatement efforts in the presence of consumers that show a certain degree of environmental concern when purchasing products. We have provided a stylized model in which we have abstracted from regulatory measures in order to focus on alternative market-driven drivers of environmental innovation. In particular, we have introduced a proenvironmental component into a vertically differentiated model in which consumers value the intrinsic quality of a certain product. This was done by resorting to the theory of relative preferences, which combines sociological and psychological aspects to explain consumers' purchasing decisions for products which provide some moral gratification in addition to satisfy material needs.

We have found that the interplay between the intensity of market competition, the level of consumers' income disparity, and their degree of environmental concern plays a key role in the technological choice of the green producer. A simple prescription arises: the adoption of cleaner production, that entails a variable cost disadvantage for the environmental friendly firm with respect to the brown firm, can be discouraged by a low average WTP for quality in the market (low average income) and by tough competition, while it can be spurred by the moral/social incentive to proenvironmental behavior.

Our analysis is in line with the objectives of different initiatives that have been recently supported in order to increase the proactive role of consumers in affecting environmental strategies. As reported in Future Earth 2025, one of the key focal challenges is to "encourage sustainable consumption and production patterns that are equitable by understanding the social and environmental impacts of consumption of all resources, opportunities for decoupling

\footnotetext{
25 It is worth remarking that in the covered duopoly, the intensity of social preferences is such that a price switch emerges and, in spite of its lower hedonic quality, the price of the green variant turns out to be higher than the price of the brown good.

${ }^{26}$ For more information, please visit http://www.futureearth.org/news/future earth-2025-vision-sets-framework-programmes-contribution-global-sustainabledevelopment.
}

resource use from growth in well-being, and options for sustainable development pathways and related changes in human behavior."26 An in-depth analysis of this issue from an empirical viewpoint is left for future research.

\section{Appendix A}

Consider as a starting point an uncovered market in which both firms are active. Demands are defined as $x_{L}=\left(\theta_{H}-\theta_{L}\right) / b$ and $x_{H}=\left(b-\theta_{H}\right) / b$, and profit functions are given by $\pi_{H}=x_{H} \cdot p_{H}$ and $\pi_{L}=\left(p_{L}-c\right) x_{L}$. Equilibrium prices can be easily obtained:

$p_{L}^{C}=\frac{2 c q_{H}+\left(q_{H}-q_{L}\right)\left(2 \gamma q_{H}+b q_{L}\right)}{4 q_{H}-q_{L}}$,

$p_{H}^{C}=\frac{c q_{H}+\left(q_{H}-q_{L}\right)\left[2 b q_{H}-\gamma\left(3 q_{H}-q_{L}\right)\right]}{4 q_{H}-q_{L}}$,

where additional superscript $C$ indicates Cleaner (technology), as we also specified in the main text. First, we verify that:

$p_{L}^{C} \geq c \Leftrightarrow \gamma \geq \frac{c\left(2 q_{H}-q_{L}\right)-b q_{L}\left(q_{H}-q_{L}\right)}{2 q_{H}\left(q_{H}-q_{L}\right)} \equiv \underline{\gamma}$,

$p_{H}^{C} \geq 0 \Leftrightarrow \gamma \leq \frac{q_{H}\left[2 b\left(q_{H}-q_{L}\right)+c\right]}{\left(q_{L}-3 q_{H}\right)\left(q_{L}-q_{H}\right)} \equiv \bar{\gamma}$,

with

$\underline{\gamma}>0 \Leftrightarrow b<b_{0} \equiv \frac{c\left(2 q_{H}-q_{L}\right)}{q_{L}\left(q_{H}-q_{L}\right)}$,

$\bar{\gamma}>\underline{\gamma} \Leftrightarrow b>\underline{b} \equiv \frac{c}{\left(q_{H}+q_{L}\right)}$,

and $b_{0}>\underline{b}$. Moreover, we have to demonstrate that the market is uncovered, i.e. $0<\theta_{L}<\theta_{H}<b$. By substituting $p_{L}^{C}$ and $p_{H}^{C}$ into (2) and (3), we obtain $\theta_{H}^{C}$ and $\theta_{L}^{C}$ and the following conditions:

$\theta_{H}^{C} \leq b \Leftrightarrow \gamma \leq \bar{\gamma}, \theta_{L}^{C} \leq \theta_{H}^{C} \Leftrightarrow \gamma \geq \underline{\gamma}$,

$\theta_{L}^{C} \geq 0 \Leftrightarrow \gamma \leq \widehat{\gamma} \equiv \frac{2 c q_{H}+b\left(q_{H}-q_{L}\right) q_{L}}{\left(2 q_{H}-q_{L}\right)\left(q_{H}-q_{L}\right)}$,

where the precise values of $\theta_{L}^{C}$ and $\theta_{H}^{C}$ are available upon request. Moreover, observe that:

$\widehat{\gamma}>\bar{\gamma} \Leftrightarrow b<\widehat{b} \equiv \frac{c q_{H}}{\left(q_{H}-q_{L}\right)^{2}}$, with $\widehat{b}>\underline{b}$.

By considering $b>\widehat{b}$, threshold values $\bar{\gamma}$ and $\underline{b}$ become irrelevant. This explains the parametric restriction adopted in Lemma 1 for the uncovered market that ensures that $0<\theta_{L}^{C}<\theta_{H}^{C}<b$. Equilibrium demands are as follows:

$x_{L}^{C}=\frac{q_{H}\left[\left(q_{H}-q_{L}\right)\left(2 \gamma q_{H}+b q_{L}\right)-c\left(2 q_{H}-q_{L}\right)\right]}{b q_{L}\left(4 q_{H}-q_{L}\right)\left(q_{H}-q_{L}\right)}$,

$x_{H}^{C}=\frac{c q_{H}+\left(q_{H}-q_{L}\right)\left[2 b q_{H}-\gamma\left(3 q_{H}-q_{L}\right)\right]}{b\left(4 q_{H}-q_{L}\right)\left(q_{H}-q_{L}\right)}$,

while equilibrium profits are reported in the main text.

Now consider what happens for $\gamma \geq \widehat{\gamma}$, which is indeed possible only when $b \geq \widehat{b}$. The result is $\theta_{L}^{C} \leq 0$, and therefore the market is covered. An interior duopoly solution with covered market cannot be sustained at equilibrium, as it can be easily verified. In such a case, therefore, a duopoly with the market covered at the limit 
becomes the unique equilibrium candidate. This equilibrium configuration is characterized by constrained price competition. As the market is covered at the limit, the indifferent consumer $\theta_{L}$ defined in (2) is set equal to zero, and demand functions are $x_{L}=\theta_{H} / b$ and $x_{H}=\left(b-\theta_{H}\right) / b$. Accordingly, the equilibrium price of the green good is given by $p_{L}^{C_{c o v}}=\gamma\left(q_{H}-q_{L}\right)>c$. Additional specification cov defines equilibrium variables in case of covered market. Inserting $p_{L}^{C_{c o v}}$ into the best reply of the high quality firm and solving, we obtain $p_{H}^{C_{\text {cov }}}=(b-\gamma)\left(q_{H}-q_{L}\right) / 2>0$ if $\gamma<b$. Hence, when $\gamma \geq \widehat{\gamma}$, there is still room for both producers and the market is covered at the limit only when $\gamma<b$. Equilibrium demands are given by $x_{L}^{C_{c o v}}=(b+\gamma) / 2 b$ and $x_{H}^{C_{c o v}}=(b-\gamma) / 2 b$; equilibrium profits are provided in the main text.

\section{Appendix B}

We start by assuming that both firms are active in an uncovered market. Demands are then defined as $x_{L}=\left(\theta_{H}-\theta_{L}\right) / b$ and $x_{H}=\left(b-\theta_{H}\right) / b$ with $\theta_{L}$ and $\theta_{H}$ defined in the main text. The pair of candidate equilibrium prices can be easily obtained:

$p_{L}^{E}=\frac{\left(q_{H}-q_{L}\right)\left(2 \gamma q_{H}+b q_{L}\right)}{4 q_{H}-q_{L}}>0$,

$p_{H}^{E}=\frac{\left(q_{H}-q_{L}\right)\left[2 b q_{H}-\gamma\left(3 q_{H}-q_{L}\right)\right]}{4 q_{H}-q_{L}}$.

where superscript $E$ denotes the equilibrium value obtained under end-of-the-pipe technology. In order for the duopoly to hold at equilibrium, the following conditions must simultaneously hold:

$\pi_{L}^{E} \geq 0$

$\Leftrightarrow \gamma \geq \frac{\left(4 q_{H}-q_{L}\right) \sqrt{F b q_{H} q_{L}\left(q_{H}-q_{L}\right)}-b q_{H} q_{L}\left(q_{H}-q_{L}\right)}{2 q_{H}^{2}\left(q_{H}-q_{L}\right)} \equiv \underline{\gamma}^{\prime}$,

$p_{H}^{E} \geq 0 \Leftrightarrow \gamma \leq \frac{2 b q_{H}}{\left(q_{L}-3 q_{H}\right)} \equiv \bar{\gamma}^{\prime}$,

with:

$\underline{\gamma}^{\prime}>0 \Leftrightarrow b<b_{0}^{\prime} \equiv \frac{F\left(4 q_{H}-q_{L}\right)^{2}}{q_{H} q_{L}\left(q_{H}-q_{L}\right)}$,

$\bar{\gamma}^{\prime}>\underline{\gamma^{\prime}} \Leftrightarrow b>\underline{b^{\prime}} \equiv \frac{F q_{L}\left(3 q_{H}-q_{L}\right)^{2}}{q_{H}\left(q_{H}-q_{L}\right)\left(q_{H}+q_{L}\right)^{2}}$,

and $b_{0}^{\prime}>\underline{b^{\prime}}$. We also need to demonstrate that the market is uncovered, and that both goods have positive demands, i.e. $0<\theta_{L}<\theta_{H}<b$. By substituting $p_{L}^{E}$ and $p_{H}^{E}$ into (2) and (3) we obtain $\theta_{L}^{E}$ and $\theta_{H}^{E}$ and the following conditions:

$\theta_{H}^{E} \leq b \Leftrightarrow \gamma \leq \bar{\gamma}^{\prime} ; \theta_{L}^{E} \leq \theta_{H}^{E}$ always;

$\theta_{L}^{E} \geq 0 \Leftrightarrow \gamma \leq \widehat{\gamma}^{\prime} \equiv \frac{b q_{L}}{2 q_{H}-q_{L}}$.

The precise values of $\theta_{L}^{E}$ and $\theta_{H}^{E}$ are available upon request. For every value of $b$, notice that $\widehat{\gamma}^{\prime}<\bar{\gamma}^{\prime}$ when $q_{H} / q_{L} \in(1,2)$. For this reason, we can neglect $\bar{\gamma}^{\prime}$ from the relevant set of threshold values. Moreover, observe that

$\widehat{\gamma}^{\prime}>\underline{\gamma^{\prime}} \Leftrightarrow b>\frac{F\left(2 q_{H}-q_{L}\right)^{2}}{q_{H} q_{L}\left(q_{H}-q_{L}\right)} \equiv \widehat{b}^{\prime}$, with $\widehat{b}^{\prime}<b_{0}^{\prime}$.
Hence, in $b>\widehat{b}^{\prime}$ the duopoly is sustained by an interior equilibrium when $\gamma \in\left[\max \left\{0, \underline{\gamma}^{\prime}\right\}, \widehat{\gamma}^{\prime}\right)$, given that $0<\theta_{L}^{E}<\theta_{H}^{E}<b$. Equilibrium demands are:

$x_{L}^{E}=\frac{q_{H}\left(2 \gamma q_{H}+b q_{L}\right)}{b q_{L}\left(4 q_{H}-q_{L}\right)}, x_{H}^{E}=\frac{2 b q_{H}-\gamma\left(3 q_{H}-q_{L}\right)}{b\left(4 q_{H}-q_{L}\right)}$,

while equilibrium profits are reported in the text.

Consider now what happens when $\gamma \geq \widehat{\gamma}^{\prime}$. This implies that $\theta_{L}^{E} \leq 0$; the equilibrium candidate is a duopoly with the market covered at the limit. By imposing $\theta_{L}=0$, demand functions become $x_{L}=\theta_{H} / b$ and $x_{H}=\left(b-\theta_{H}\right) / b$. Equilibrium prices are the same as under cleaner production, i.e. $p_{L}^{E_{c o v}}=p_{L}^{C_{c o v}}>0 \quad$ and $p_{H}^{E_{c o v}}=p_{H}^{C_{\text {cov }}}>0 \Leftrightarrow \gamma<b$, with $b>\widehat{\gamma}^{\prime}$. Also equilibrium demands do not vary: $x_{L}^{E_{c o v}}=x_{L}^{C_{c o v}}$ and $x_{H}^{E_{c o v}}=x_{H}^{C_{\text {cov }}}$. Hence, the equilibrium profit for the brown producer remains the same: $\pi_{H}^{E_{c o v}}=\pi_{H}^{C_{c o v}}$. The profit of the green firms is instead modified, and it results in:

$$
\begin{aligned}
& \pi_{L}^{E_{c o v}}=\frac{\gamma(b+\gamma)\left(q_{H}-q_{L}\right)}{2 b}-F \geq 0 \Leftrightarrow \gamma \geq \frac{\sqrt{b} \sqrt{8 F+b\left(q_{H}-q_{L}\right)}}{2 \sqrt{\left(q_{H}-q_{L}\right)}}-\frac{b}{2} \equiv \underline{\gamma^{\prime \prime}}, \\
& \widehat{\gamma}^{\prime}>\underline{\gamma^{\prime \prime}} \Leftrightarrow b>b_{1} \text {, and } b>\underline{\gamma^{\prime \prime}} \Leftrightarrow b>\frac{\sqrt{F}\left(2 q_{H}-q_{L}\right)}{\sqrt{q_{H} q_{L}\left(q_{H}-q_{L}\right)}} \equiv b_{2}, \text { with } b_{2}<b_{1} .
\end{aligned}
$$

However, given that $\widehat{b}^{\prime}>b_{1}\left(>b_{2}\right)$, we can exclude parameter $\gamma^{\prime \prime}$ from the relevant set of threshold values. It follows that a corner duopoly equilibrium with covered market appears in $\gamma \in\left[\widehat{\gamma}^{\prime}, b\right)$.

\section{Appendix C}

On the one hand, we obtain that:

$$
\begin{aligned}
& \widehat{b}-\widehat{b}^{\prime} \gtreqless 0 \Leftrightarrow F \gtreqless \frac{c q_{H} q_{L}}{\left(q_{H}-q_{L}\right)\left(2 q_{H}-q_{L}\right)^{2}} \equiv F_{0}, \\
& \underline{\gamma}^{\prime}-\underline{\gamma} \gtreqless 0 \Leftrightarrow F \gtreqless \frac{c^{2} q_{H}\left(2 q_{H}-q_{L}\right)^{2}}{b q_{L}\left(q_{H}-q_{L}\right)\left(4 q_{H}-q_{L}\right)^{2}} \equiv F_{1},
\end{aligned}
$$

with $F_{0}>F_{1}$ in $b>\max \left\{\widehat{b}, \widehat{b}^{\prime}\right\}$. Hence, the comparisons between $\widehat{b}$ and $\widehat{b}^{\prime}$ and between $\gamma$ and $\gamma^{\prime}$ depends of the relative intensity of $F$ versus $c$. On the other hand, it is immediate to prove that $\widehat{\gamma}^{\prime}<\widehat{\gamma}$ for each $c>0$, given that $\lim _{c \rightarrow 0} \widehat{\gamma}=\widehat{\gamma}^{\prime}$.

\section{Appendix D}

First, consider the conditions under which these $b$-thresholds are positive: $b^{c o v}=\frac{c \gamma}{(2 F-c)}>0 \Leftrightarrow \frac{F}{c}>\frac{1}{2}$. Given that $\frac{F}{c}>\frac{1}{2}$, the denominator of $b^{F}$ is positive (as $\frac{1}{2}>\frac{2 q_{H}\left(2 q_{H}-q_{L}\right)}{\left(4 q_{H}-q_{L}\right)^{2}}$ ), then $b^{F}>0 \Leftrightarrow$ $4 q_{H}\left(q_{H}-q_{L}\right) \gamma>c\left(2 q_{H}-q_{L}\right)$. Comparing the two $b$-thresholds we find that:

$$
\begin{aligned}
b^{F}-b^{c o v}= & \frac{c q_{H}\left(2 q_{H}-q_{L}\right)\left[4 q_{H}\left(q_{H}-q_{L}\right) \gamma-c\left(2 q_{H}-q_{L}\right)\right]}{q_{L}\left(q_{H}-q_{L}\right)\left[\left(4 q_{H}-q_{L}\right)^{2} F-2 c q_{H}\left(2 q_{H}-q_{L}\right)\right]} \\
& -\frac{c \gamma}{(2 F-c)} .
\end{aligned}
$$

While $b^{\text {cov }}$ does not depend on $q_{H} / q_{L}$, we show that $b^{F}$ is increasing in $q_{H}$, given $q_{L}$, in the relevant range of parameters 
$\left.\left.q_{H} / q_{L} \in\right] 1,2\right]$. To this aim, without loss of generality, let us normalize $q_{L}$ to one. Then,

\section{$\frac{\partial b^{F}}{\partial q_{H}}>0$}

Indeed, $\partial b^{F} / \partial q_{H}$ is a polynomial with 4 terms:

$$
\begin{aligned}
\frac{\partial b^{F}}{\partial q_{H}}= & \underbrace{\left(\left(2 q_{H}-1\right)\left(4 q_{H}-1\right)\left(-2 q_{H}+4 q_{H}^{2}+1\right)\right) F c}_{A} \\
& -\underbrace{2 q_{H}^{2}\left(2 q_{H}-1\right)^{2} c^{2}}_{B} \\
& +\underbrace{\left(8 \gamma q_{H}\left(4 q_{H}-1\right)\left(-3 q_{H}+4 q_{H}^{2}+1\right)\left(q_{H}-1\right)^{2}\right) F}_{D} \\
& +\underbrace{\left(-8 \gamma q_{H}^{2}\left(2 q_{H}-1\right)^{2}\left(q_{H}-1\right)^{2}\right) c}_{D}
\end{aligned}
$$

Since $A-B>0$ and $D-G>0$, then it follows that $\partial b^{F} / \partial q_{H}>0$. Notice also that there exists a value of $q_{H}$, say $q_{H}^{\circ}$, with $q_{H}^{\circ}=\frac{1}{4 \gamma}(c+$ $\left.2 \gamma+\sqrt{4 \gamma^{2}+c^{2}}\right)$, such that $b^{F}\left(q_{H}^{\circ}\right)=0$. Thus, it immediately follows that there exists a value of $q_{H}$, say $\tilde{q}_{H}$, such that $b^{F}\left(\tilde{q}_{H}\right)=b^{\operatorname{cov}}\left(\tilde{q}_{H}\right)$ for any $q_{H}<\tilde{q}_{H}$ then $b^{F}<b^{c o v}$, while $b^{F} \geq b^{\operatorname{cov}}$ otherwise namely for any $q_{H} \geq \tilde{q}_{H}$.

\section{References}

Abe, K., Zhao, L., 2005. Endogenous international joint ventures and the environment. J. Int. Econ. 67, 221-240.

Akerlof, G., 1997. Social distance and social decisions. Econometrica 65, 1005-1027. Alexopoulos, M., Sapp, S., 2006. Exploring the behavior of economic agents: the role of relative preferences. Econ. Bull. 12, 1-7.

Amacher, G.S., Koskela, E., Ollikainen, M., 2004. Environmental quality competition and eco-labeling. J. Environ. Econ. Manag. 47, 284-306.

André, F.J., González, P., Porteiro, N., 2009. Strategic quality competition and the porter hypothesis. J. Environ. Econ. Manag. 57, 182-194.

Andreoni, J., 1988. Privately provided public goods in a large economy: the limits of altruism. J. Public Econ. 35, 57-73.

Andreoni, J., 1990. Impure altruism and donations to public goods: a theory of warm-glow giving. Econ. J. 100, 464-477.

Andreoni, J., Bernheim, D., 2009. Social image and 50-50 norm: a theoretical and experimental analysis of audience effects. Econometrica 77, 1607-1636.

Arora, S., Gangopadhyay, S., 1995. Toward a theoretical model of voluntary overcompliance. J. Econ. Behav. Organ. 28, 289-309.

Bansal, S., Gangopadhyay, S., 2003. Tax/subsidy policies in the presence of environmentally aware consumers. J. Environ. Econ. Manag. 45, 333-355.

Bayindir-Upmann, T., 2003. Strategic environmental policy under free entry of firms. Rev. Int. Econ. 11, 379-396.

Bénabou, R., Tirole, J., 2006. Incentives and prosocial behavior. Am. Econ. Rev. 96, 1652-1678.

Ben Elhadj, N., Tarola, O., 2015. Relative quality-related (dis)utility in vertically differentiated oligopoly with an environmental externality. Environ. Dev. Econ. 20, 354-379.

Ben Elhadj, N., Gabszewicz, J.J., Tarola, O., 2015. Social awareness and price competition. Int. J. Econ. Theory 11, 75-88.

Bergstrom, T., 1995. On the evolution of altruistic ethical rules for siblings. Am. Econ. Rev. 85, 58-81.

Borghesi, S., 2001. The environmental kuznets curve: a critical survey. In: Franzini, M., Nicita, A. (Eds.), Economic Institutions and Environmental Policy. Ashgate Publishing, Farnham.

Boyce, J., 1994. Inequality as a cause of environmental degradation. Ecol. Econ. 11, $169-178$.

Brekke, K.A., Kverndokk, S., Nyborg, K., 2003. An economic model of moral motivation. J. Public Econ. 87, 1967-1983.

Calel, R., 2011. Market-based instruments and technology choices: a synthesis. In: Grantham Research Institute on Climate Change and the Environment. Working Paper Series, vol. 57.

Carlsson, F., Garcia, J., Löfgren, A., 2010. Conformity and the demand for environmental goods. Environ. Resour. Econ. 47, 407-421.

Christin, C., Nicolaï, J.-P., Pouyet, J., 2013. Pollution Permits, Imperfect Competition and Abatement Technologies. CER-ETH: Center of Economic Research at ETH Zurich. Working Paper 13/186.

Clemenz, G., 2010. Eco-labeling and horizontal product differentiation. Environ.
Resour. Econ. 45, 481-497.

Cole, M.A., Elliot, R.J.R., Fredriksson, G., 2009. Institutionalized pollution havens. Ecol. Econ. 68, 1239-1256.

Conrad, K., 2005. Price competition and product differentiation when consumers care for the environment. Environ. Resour. Econ. 31, 1-19.

Copeland, B.R., Taylor, M.S., 2004. Trade, growth, and the environment. J. Econ. Lit. 42, 7-71.

Deltas, G., Harrington, D.R., Khanna, M., 2013. Oligopolies with (somewhat) environmentally conscious consumers: market equilibrium and regulatory intervention. J. Econ. Manag. Strategy 22, 640-667.

Denicolò, V., 1999. Pollution-reducing innovations under taxes or permits. Oxf. Econ. Pap. 51, 184-199.

Dietz, T., Fitzgerald, A., Shwom, R., 2005. Environmental values. Annu. Rev. Environ. Resour. 30, 335-372.

Dinda, S., 2004. Environmental Kuznets curve hypothesis: a survey. Ecol. Econ. 49, $431-455$.

Dinda, S., 2005. A theoretical basis for the environmental Kuznets curve. Ecol. Econ. 53, 403-413.

Eriksson, C., 2004. Can green consumerism replace environmental regulation? a differentiated products example. Resour. Energy Econ. 26, 281-293.

Frondel, M., Horbach, J., Rennings, K., 2007. End-of-pipe or cleaner production? An empirical comparison of environmental innovation decisions across OECD countries. Bus. Strategy Environ. 16, 571-584.

Gabszewicz, J., Thisse, J.F., 1979. Price competition, quality and income disparities. J. Econ. Theory 20, 340-359.

García-Gallego, A., Georgantzís, N., 2009. Market effects of changes in consumers' social responsibility. J. Econ. Manag. Strategy 18, 235-262.

Garcia, F., Vergari, C., 2016. Revealing incentives for compatibility provision in vertically differentiated network industries. J. Econ. Manag. Strategy 25, $720-749$.

Greaker, M., 2003. Strategic environmental policy when the governments are threatened by relocation. Resour. Energy Econ. 25, 141-154.

Grilo, I., Shy, O., Thisse, J., 2001. Price competition when consumer behaviour is characterized by conformity or vanity. J. Public Econ. 80, 385-408.

Heffner, R., Kurani, K.S., Turrentine, T.S., 2007. Symbolism in California's early market for hybrid electric vehicles. Transp. Res. Part D 12, 396-413.

Hemmelskamp, J., 1997. Environmental policy instruments and their effects on innovation. Eur. Plan. Stud. 5, 177-194.

Ikefuji, M., Itaya, J., Okamura, M., 2016. Optimal emission tax with endogenous location choice of duopolistic firms. Environ. Resour. Econ. 65, 463-485.

Johnstone, N., Hascic, I., Popp, D., 2010. Renewable energy policies and technological innovation: evidence based on patent counts. Environ. Resour. Econ. 45, 133-155.

Kayalica, O., Lahiri, S., 2005. Strategic environmental policies in the presence of foreign direct investment. Environ. Resour. Econ. 30, 1-21.

Lambertini, L., Tampieri, A., 2012. Vertical differentiation in a Cournot industry: the porter hypothesis and beyond. Resour. Energy Econ. 34, 374-380.

Litina, A., Moriconi, S., Zanaj, S., 2016. The cultural transmission of environmental value: a comparative approach. World Dev. 84, 131-148.

Lombardini-Riipinen, C., 2005. Optimal tax policy under environmental quality competition. Environ. Resour. Econ. 32, 317-336.

Magnani, E., 2000. The environmental Kuznets curve, environmental protection policy and income distribution. Ecol. Econ. 32, 431-443.

Manner, M., Gowdy, J., 2010. The evolution of social and moral behavior: evolutionary insights for public policy. Ecol. Econ. 69, 753-761.

Mantovani, A., Vergari, C., 2017. Environmental vs hedonic quality: which policy can help in lowering pollution emissions? Environ. Dev. Econ. http://dx.doi.org/ 10.1017/S1355770X16000371. Published online: 17 February 2017.

Mantovani, A., Tarola, O., Vergari, C., 2016. Hedonic and environmental quality: a hybrid model of product differentiation. Resour. Energy Econ. 45, 99-123.

Markusen, J.R., Morey, E.R., Olewiler, N.D., 1993. Environmental policy when market structure and plant location are endogenous. J. Environ. Econ. Manag. 24, 69-86.

Markusen, J.R., Morey, E.R., Olewiler, N.D., 1995. Competition in regional environmental policies when plant locations are endogenous. J. Public Econ. 56, 55-77.

Montero, J.P., 2002. Permits, standards, and technology innovation. J. Environ. Econ. Manag. 44, 23-44.

Montero, J.P., 2011. A note on environmental policy and innovation when governments cannot commit. Energy Econ. 33 (Suppl.), S13-S19.

Moraga-Gonzalez, J.L., Padron-Fumero, N., 2002. Environmental policy in a green market. Environ. Resour. Econ. 22, 419-447.

Motta, M., Thisse, J.-F., 1994. Does environmental dumping lead to delocation? Eur. Econ. Rev. 38, 563-576.

Mussa, M., Rosen, S., 1978. Monopoly and product quality. J. Econ. Theory 18, $301-317$.

Nicolaï, J.-P., Meunier, G., 2014. Higher Costs for Higher Profits: a General Assessment and an Application to Environmental Regulations. CER-ETH - Center of Economic Research at ETH Zurich. Economic Working Paper 14/191.

Nyborg, K., Howarth, R.B., Brekke, K.A., 2006. Green consumers and public policy: on socially contingent moral motivation. Resour. Energy Econ. 28, 351-366.

Ostrom, E., 2000. Collective action and the evolution of social norms. J. Econ. Perspect. 14, 137-158.

Owen, A.L., Videral, J., 2006. Civic cooperation, proenvironment attitudes, and behavioral intentions. Ecol. Econ. 58, 814-829.

Petrakis, E., Xepapadeas, A., 2003. Location decisions of a polluting firm and the 
time consistency of environmental policy. Resour. Energy Econ. 25, 197-214.

Pfaff, A., Chauduri, S., Nye, H., 2004. Endowments, preferences, technologies and abatement: growth-environment microfoundations. Int. J. Glob. Environ. Issues 4, 209-228.

Porter, M., 1990. The Competitive Advantage of Nations. Free Press, New York.

Porter, M., van der Linde, C., 1995. Toward a new conception of the environmentcompetitiveness relationship. J. Econ. Perspect. 9, 97-118.

Reichmann, T., 2006. Mixed motives in a cournot game. Econ. Bull. 4, 1-8.

Requate, T., 2005. Timing and commitment of environmental policy, adoption of new technology, and repercussions on R\&D. Environ. Resour. Econ. 31, 175-199.

Requate, T., Unold, W., 2003. Environmental policy incentives to adopt advanced abatement technology - will the true ranking please stand up? Eur. Econ. Rev. 47, 125-146.

Sanna-Randaccio, F., Sestini, R., 2012. The impact of unilateral climate policy with endogenous plant location and market size asymmetry. Rev. Int. Econ. 20, 580-599.

Sanna-Randaccio, F., Sestini, R., Tarola, O., 2016. Unilateral climate policy and foreign direct investment with firm and country heterogeneity. Environ. Resour. Econ. http://dx.doi.org/10.1007/s10640-015-9990-1. First Online: 05 January 2016.
Schumacher, I., 2015. The endogenous formation of an environmental culture. Eur Econ. Rev. 76, 200-221.

Scotchmer, S., 2011. Cap-and-trade, emissions taxes, and innovation. Innov. Policy Econ. 11, 29-54.

Shaked, A., Sutton, J., 1982. Relaxing price competition through product differentiation. Rev. Econ. Stud. 49, 3-13.

Steg, L., de Groot, J.I.M., 2012. Environmental values. In: Clayton, S. (Ed.), The Oxford Handbook of Environmental and Conservation Psychology. Oxford University Press, New York, pp. 81-92.

Tirole, J., 1988. The Theory of Industrial Organization. MIT Press, Cambridge, MA.

Turaga, R.M.R., Howarth, R.B., Borsuk, M.E., 2010. Pro-environmental behavior: rational choice meets moral motivation. Ann. N. Y. Acad. Sci. 1185, 211-224.

Ulph, A., Valentini, L., 2001. Is environmental dumping greater when plants are footloose? Scand. J. Econ. 103, 673-688.

Veblen, T., 1899. Theory of the Leisure Class: an Economic Study in the Evolution of Institutions. Macmillan, New York.

Vona, F., Patriarca, F., 2010. Income inequality and the development of environmental technologies. Ecol. Econ. 70, 2201-2213.

Zeng, D.-Z., Zhao, L., 2009. Pollution havens and industrial agglomeration. J. Environ. Econ. Manag. 58, 141-154. 